\title{
PhD courses and the intersectoral experience: a comprehensive survey
}

\author{
Alexandra Kosvyra ${ }^{1}$, Dimitris Filos ${ }^{1}$, Nicola Mountford ${ }^{2}$, Tara Cusack ${ }^{3}$, Minna \\ Isomursu $^{4}$, Ioanna Chouvarda ${ }^{1}$ \\ ${ }^{1}$ Laboratory of Computing, Medical Informatics and Biomedical Imaging Technologies, \\ School of Medicine, Aristotle University of Thessaloniki, Thessaloniki, Greece, ${ }^{2}$ Maynooth \\ University School of Business, Maynooth, Ireland ${ }^{3}$ School of Public Health, Physiotherapy \\ and Sports Science, University College, Dublin, Ireland, ${ }^{4}$ University of Oulu, Oulu, Finland.
}

\begin{abstract}
It has been found that most PhD graduates (>85\%) do not achieve a long-term academic career and thus there is a growing need to re-imagine PhD education that incentivizes doctoral students to engage with research consumers, not only within their discipline, but also, across other disciplines and sectors to have real social impact for an improved society. The aim of this work is to identify intersectoral/interdisciplinary courses that are considered to broaden student career outside and inside academia. For this purpose, a survey was designed to identify modules which lead to the improvement of students' skills while an analysis of their attributes was also performed. Two target groups have been considered: (a) young researchers and (b) program directors each of which can provide different information regarding the courses of interest. 52 students and 11 directors from 5 European Universities, participated in the study. An absence of such courses in the standard PhD program was observed, while any intersectoral/interdisciplinary activities were conducted outside the PhD program, and organized by collaboration of academia and other organizations. The survey findings reveal the need to restructure the PhD programs.
\end{abstract}

Keywords: PhD courses; career enhancement; intersectorality; interdisciplinarity. 


\section{Introduction}

$\mathrm{PhD}$ studies are widely considered as the highest level of education, deepening knowledge and skills in a specific field of research. Interdisciplinary $\mathrm{PhD}$ programs have, however, been suggested that follow a T-shape approach. This approach considers the traditional $\mathrm{PhD}$ expertise and skill coupled with additional learning as part of a multi-disciplinary and intersectoral community (Mountford et al., 2017). With intersectoral training we mean training that is organized together with actors from different sectors, including academy, industry, public sector and/or 3rd sector. Several challenges have been identified and solutions have been proposed in (Chouvarda et al., 2019) regarding interprofessional and interdisciplinary education and teamwork in Connected Health $(\mathrm{CH})$ research in particular. These focus on overcoming disciplinary boundaries, recognizing that $\mathrm{CH}$ research involves an intersectoral ecosystem. The entire ecosystem can only benefit from $\mathrm{CH}$ post-doctoral researchers who move from academia to industry and apply their knowledge and skills in $\mathrm{CH}$ research, development, and entrepreneurship. Graduate students may not, however, have some of the broader skills required by industry, especially in engineering and medicine (Cui \& Harshman, 2020; Lieu Tran et al., 2019). PhD students can, however, take steps to bridge the gaps between traditional academic $\mathrm{PhD}$ training, or even interdisciplinary $\mathrm{PhD}$ training in $\mathrm{CH}$, and employer expectations of post-doctoral researchers as professionals in the $\mathrm{CH}$ industry.

To that end, a survey was undertaken to identify intersectorally designed/delivered modules and their attributes, which are available to $\mathrm{PhD} /$ Postdoctoral students and help them broaden their career prospects beyond academia. With the results of this survey, we aim to identify: (a) what are the modules that people involved in $\mathrm{PhD}$ studies find more useful in terms of career enhancement, (b) What are the attributes that made these courses successful and satisfying, (c)identify needs and gaps in PhD programs, and (d) use this information to develop innovative educational interventions.

This survey is part of the work conducted in the CHAMELEONS ${ }^{1}$ project. This project has received funding from the European Union's Horizon 2020 research and innovation program under grant agreement No 873105 . The overall aim of this project is to develop a range of interdisciplinary, inter-sectoral and international modules. These will be designed to broaden the skills of PhD graduates and improve their employability in academic and non-academic environments, considering the domain of connected health (Caulfield \& Donnelly, 2013). The purpose of this research is to improve the skills and attributes of Ph.D./Postdoctoral students so that they will have increased employment opportunities and impact on completion of their studies.

\footnotetext{
${ }^{1}$ https://www.chameleonsproject.eu/
} 


\section{Methods}

\subsection{Target Group}

We have identified two different groups of people involved in $\mathrm{PhD}$ programs. In particular: (a) Young researchers: In this category $\mathrm{PhD} \&$ Postdoc students were included. The inclusion criteria were: (i) the participants should be currently $\mathrm{PhD}$ candidates or (ii) they have finished their $\mathrm{PhD}$ in the past 5 years, (b) Research associates/ program directors: This category included all academic faculty who had been involved in the design or delivery of an intersectoral module or course.

For the study purposes two different questionnaires were developed, one per target group, in order to identify the different perspectives of the two groups in relation to the intersectorally designed courses. While the goal is to extract information about these courses, different points of view are revealed by each group.

\subsection{Design of the questionnaire}

The survey was iteratively designed with the participation of partners from Aristotle University of Thessaloniki, University of Oulu, University College Dublin and Maynooth University. For the design of the survey, an initial workshop was organized in order to define the directions that needed to be followed. In this workshop, a set of questions was proposed and discussed. In a second stage the initial questions were reviewed/refined by the partners, to decrease redundancy and increase clarity. Finally, the questionnaire was implemented and internally reviewed before final deployment.

\subsection{Deployment}

The questionnaires were developed using the online survey tool LimeSurvey ${ }^{2}$ A central installation of the tool is provided by AUTH. All processes were GDPR compliant, and the questionnaires were developed after the consultation with AUTH's Data Protection Officer and after receiving ethical approval form AUTH's ethical committee. The survey was completely anonymous, no personal information was asked from the participants and no communication information was stored or kept.

To achieve the goals of the project the questionnaires were divided into two categories: (i) General Questions and (ii) Course-specific Questions. In the first category, the questions focused on demographic characteristics of the participants and on attaining general information regarding the courses that they may have taken/developed during their studies. The interest here lies in the nature of the courses and specifically what percentage of these

\footnotetext{
${ }^{2}$ https://www.limesurvey.org/
} 
courses are internal (included in $\mathrm{PhD}$ program) or external (not included in $\mathrm{PhD}$ program), intersectoral or not, interdisciplinary or not. In the second category, the participants were asked if they had taken/directed a specific course that was useful in terms of broadening students' career prospects outside academia. For this specific course, the participants were asked to answer to questions which are divided into three subcategories: (i) Nature of the course: to obtain general information about the specific course (title, content etc.) and the nature of the course (internal/external, intersectoral/not, interdisciplinary/not), (ii) Satisfaction: to obtain information about the satisfaction of the participant regarding the specific course, (iii) Structure: to obtain information about the structure of the course (duration, interaction level, grading, etc.).

\section{Study Results}

\subsection{Young researchers}

52 young researchers participated in the survey. Regarding the universal characteristics, Figure 1 depicts the flow of information with regards to the sex, age, basic education, career plans and the courses that students consider as useful for their career enhancement. Regarding modules taken during their $\mathrm{PhD}$ studies, 84\% (44) have taken part in both internal and external courses. In $37.5 \%$ (12) of the internal PhD courses there was involvement from nonacademic tutors/speakers mostly, 91.67\% (11) as guest speakers. Guest speaker disciplines varied across modules. External activities attended by students mostly comprised seminars/webinars and conferences, $68 \%$ (26) of which were interdisciplinary.

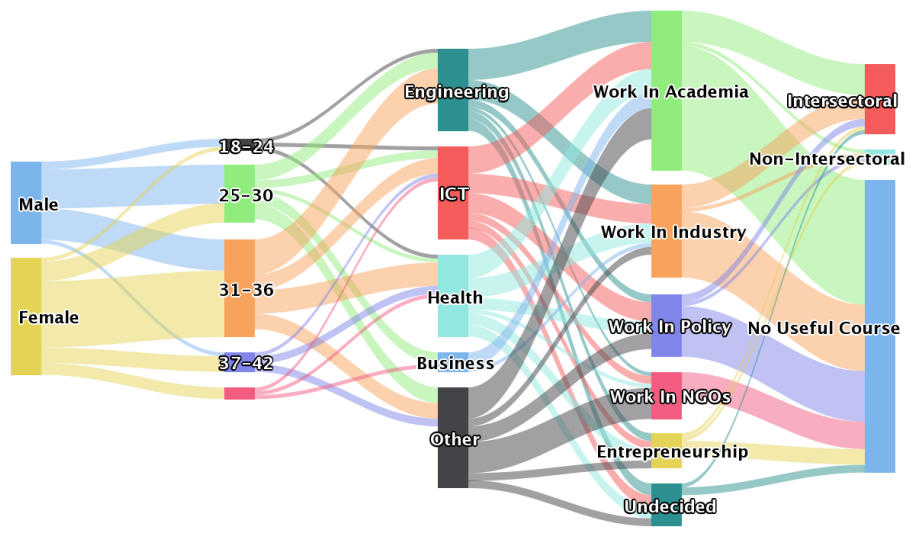

Figure 1. Universal characteristics of students; Column 1: Sex, Column 2: Age, Column 3: Background, Column4: Career Plans, Column 5: Attended courses useful for broadening non-academic career.

Of the 52 participants, only 14 (23\%) attended a course that was useful in terms of broadening their career prospects outside Academia, with only 10 of these being intersectoral in nature. 
93\% (13) of these courses were external to the student's PhD program, 57\% (8) of which were organized by academia in collaboration with industry or professional organizations. $43 \%$ (6) were interdisciplinary in the following combinations: 1 . Health and wellness, ICT, medicine, computer science, 2. Designer, Engineers, Education, Sport Science, Psychology, Business, 3. Business, science, law, communication, 4. Sports Science, Education, Psychology and Nutrition, 5. Health, Informatics.

When asked how they located the specific course, the two major routes were advertisement and supervisor referral, while in terms of important characteristics for deciding to take the course, it seems that the most important reasons were structural, since the duration and time of the course were most important with a mean value of 4.29 , followed by the structure with 3.71 and teaching/learning strategy with 3.69. The most important factors in selecting a particular course were the improvement of soft/academic skills with mean values of 3.92/3.5 respectively.

Students identified some aspects of the course in which they participated that they would like to change including the involvement of more guest speakers, better engagement between the speaker and the audience, and more activities to understand the transition that takes place between $\mathrm{PhD}$ and workplace. Also, they would like more specific and practical courses and longer learning periods. Students also identified courses that they would have liked to attend but did not have the chance including: 1. Time management, 2. Business, 3. Scientific writing and presentation.

When it came to module structure, 50\% (7) were modules that were performed on demand and not included in a specific timeline, while for 36\% (5) the duration was ' 1 week or less but more than one day'. 78\% (11) of the modules were free of charge and for $93 \%$ (13) the structure of the module included lectures. $72 \%$ (10) demanded physical presence in class and $35 \%$ (5) of the modules were publicly available. $35 \%$ of modules required an application and selection process. Finally, 50\% (7) of the modules had no evaluation and 65\% (9) offered no ECTS.

\subsection{Program directors}

Regarding the second group of participants, 11 program directors, most of them, $90 \%$ (10) has participated in the coordination of $\mathrm{PhD}$ courses, both internal and external. In $50 \%$ of the internal courses, there was involvement of non-academic speakers, mostly as guest speakers (75\%). 50\% (4) of the external courses were interdisciplinary in nature and $87.5 \%$ (7) of the directors participating in the survey encourage their students to attend such activities.

Despite this, only 30\% (3) had participated in courses that broadened students' career prospects outside Academia. All these courses, 3 in total, were external, intersectoral and interdisciplinary courses, with involvement mostly from academia. The disciplines included 
were: 1. Medicine, Engineering, 2. Social sciences, ICT, engineering, medicine, 3. Medicine, Nursing, Physiotherapy, Education Technologist, Education Developer.

These courses focused on developing specific skills, like collaborative writing and problem solving. Directors felt that these courses were attractive to students, due to their interdisciplinarity and the networking opportunities offered. $66.67 \%$ (2) of these courses were included in the standard $\mathrm{PhD}$ program, lasted less than 3 months, and there was no fee to attend. Directors suggest that these courses are more valuable when attended in the late years of students' studies. All required physical presence in class and were available to members of a certain faculty and not open. $66.67 \%$ (2) had evaluation in the form of projects and continuous assessment.

\subsection{Comparative results}

Figure 3 depicts in detail the type and structure of the courses proposed by students as compared to directors. Figure 4 depicts the importance of specific attributes of the courses as derived from the two distinct groups of participants. For both groups, the duration of a course seems to be the most important criterion for a successful course. Although students find more important the assessment strategy while directors the interdisciplinarity and networking.
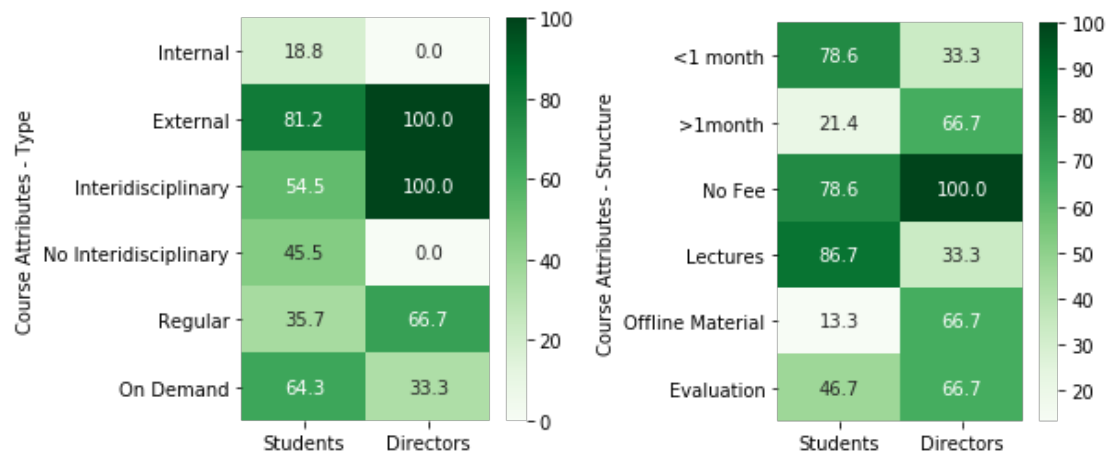

Figure 2. Comparative results for Type and Structure of the Courses. 


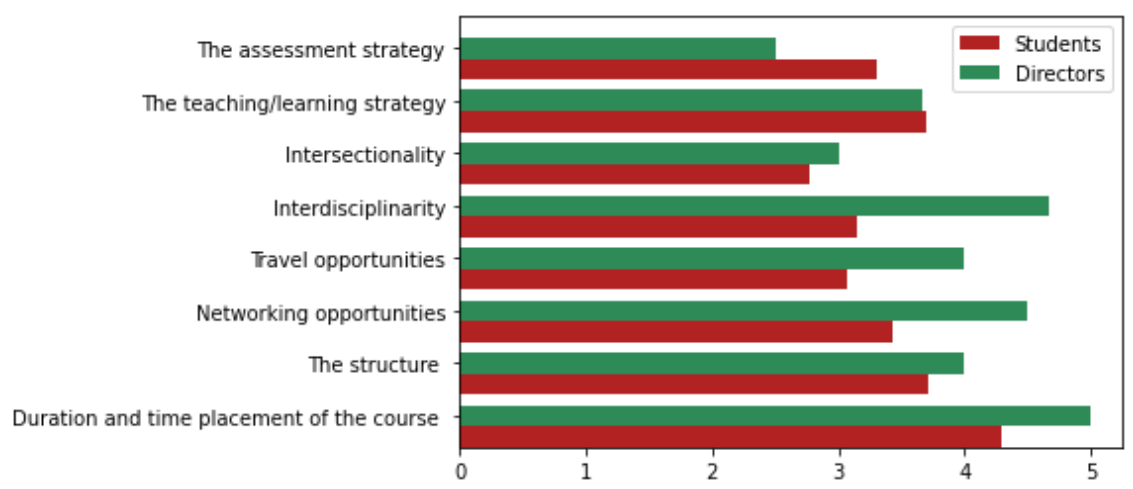

Figure 3. Comparative results for the Courses' Attributes Importance.

\subsection{Identified Modules}

The modules that were identified by the survey can be divided into 4 categories, based on the knowledge/skills they are providing. Each one of these categories can be considered as a section that can be followed by students, depending on their needs. Each module contains a variety of choices, including courses, informative videos, or guidelines. The four categories and the respective modules are depicted in detail in Figure 2.
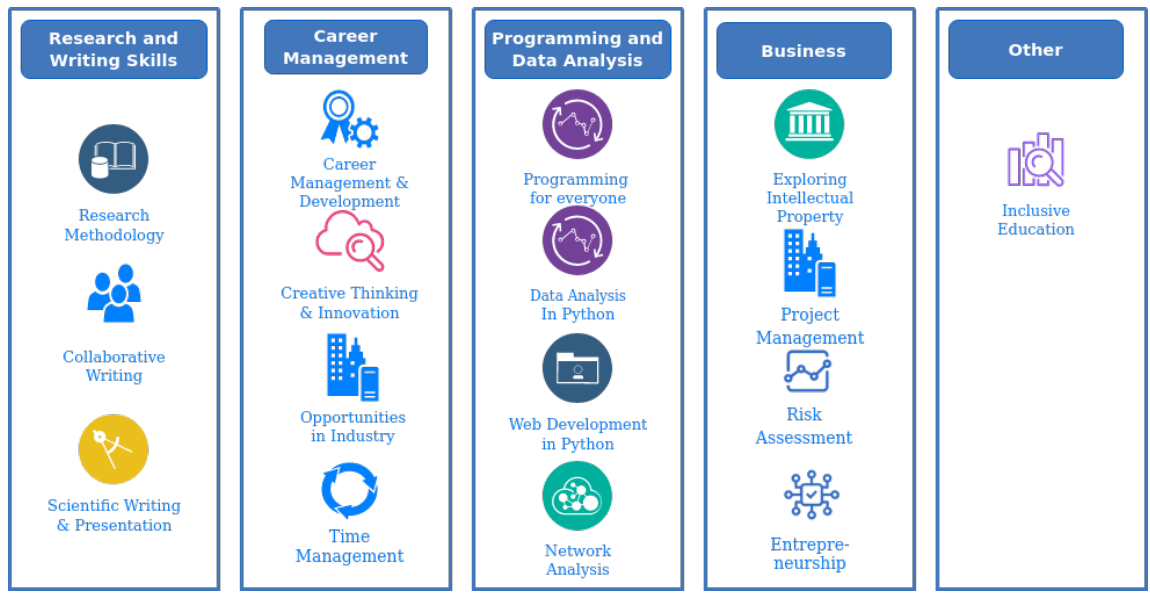

Figure 4. Modules identified through the survey.

\section{Discussion and Conclusion}

The survey results confirm the bibliographic findings that currently the $\mathrm{PhD}$ programs do not include courses or modules that aim to broaden students career opportunities outside academia (Bosch, 2018). However, interdisciplinary activities and science diversity provide 
great experience to the students (Patricio \& Santos, 2020). Students are interested in these activities as it was found that most of the courses that students attended are external activities like webinars/seminars or summer schools and directors tend to suggest to their students that they attend external activities even if these are not integrated into the program. Moreover, these courses are often organized by academic organizations in collaboration with industry and tend to be interdisciplinary. Such programs give students the opportunity to broaden their knowledge of basic education by merging different fields of science. These findings suggest that there is a need to restructure $\mathrm{PhD}$ programs.

Regarding the attributes of the courses that both groups found useful for the students' career development, this survey revealed that these groups have different perspectives. These attributes will be considered by the consortium as a baseline for the development of three intersectoral modules.

Additionally, the main reasons for selecting a specific course, seem to be structural. The students prefer brief and comprehensive courses to enrich their skills in specific fields. On the contrary, directors believe that a longer period and the involvement of more disciplines would improve the courses. Students want more practical modules that allow the direct application of the obtained knowledge. Finally, both groups believe that external, intersectoral and interdisciplinary courses are a positive addition in the $\mathrm{PhD}$ studies.

Concluding, CHAMELEONS project will take into consideration all these aspects that the participants found satisfactory in the courses they attended, to design the three modules that aim to assist students to broaden their skills and improve their employability in academic and non-academic environments. Moreover, the modules identified through this survey will be embedded in the state-of-the-art toolkit created by CHAMELEONS project. The toolkit will provide courses aiming to help $\mathrm{PhD}$ students to broaden their career opportunities outside academia and give them the opportunity to follow a structured learning strategy, with modules and material, towards improving their skills.

\section{References}

Bosch, G. (2018). Train PhD students to be thinkers not just specialists. Nature, 554(7692). https://doi.org/10.1038/d41586-018-01853-1

Chouvarda, I., Mountford, N., Trajkovik, V., Loncar-Turukalo, T., \& Cusack, T. (2019). Leveraging interdisciplinary education toward securing the future of connected health research in Europe: Qualitative study. Journal of Medical Internet Research, 21(11). https://doi.org/10.2196/14020

Cui, Q., \& Harshman, J. (2020). Qualitative Investigation to Identify the Knowledge and Skills That U.S.-Trained Doctoral Chemists Require in Typical Chemistry Positions. Journal of Chemical Education, 97(5), 1247-1255. https://doi.org/10.1021/acs.jchemed.9b01027 
Lieu Tran, T. B., Törngren, M., Nguyen, H. D., Paulen, R., Gleason, N. W., \& Duong, T. H. (2019). Trends in preparing cyber-physical systems engineers. Cyber-Physical Systems, 5(2), 65-91. https://doi.org/10.1080/23335777.2019.1600034

Mountford, N., Watts, G., Fernandez Luque, L., Chouvarda, I., Kessie, T., \& Cusack, T. (2017). An Interdisciplinary 4th Level Education Model:Connected Health. 1-8. https://doi.org/10.4995/head17.2017.5485

Patricio, M. T., \& Santos, P. (2020). Collaborative research projects in doctoral programs: a case study in Portugal. Studies in Higher Education, 45(11), 2311-2323. https://doi.org/10.1080/03075079.2019.1607282 